\title{
Single-grain cutting based modeling of abrasive belt wear in cylindrical grinding
}

\author{
Zhe HE ${ }^{1,3}$, Jianyong $\mathbf{L I}^{1,2}$, Yueming LIU ${ }^{1,2,}$, Jiwang YAN ${ }^{3}$ \\ ${ }^{1}$ School of Mechanical, Electronic and Control Engineering, Beijing Jiaotong University, Beijing 100044, China \\ ${ }^{2}$ Key Laboratory of Vehicle Advanced Manufacturing, Measuring and Control Technology, Ministry of Education, Beijing 100044, China \\ ${ }^{3}$ Department of Mechanical Engineering, Faculty of Science and Technology, Keio University, Hiyoshi 3-14-1, Kohoku-ku, Yokohama \\ 223-8522, Japan
}

Received: 19 July 2018 / Revised: 26 December 2018 / Accepted: 07 February 2019

(C) The author(s) 2019.

\begin{abstract}
A systematic wear model of the cylindrical grinding process with an alumina abrasive belt from the perspective of single grain sliding wear was established in this study. The model consists of three parts: a single cutting force model derived by applying a stress integration method, a single grain wear height analysis based on the wear rate of alumina, and a grinding mileage prediction of multiple grains with Gaussian distributed protrusion heights. Cutting force, single grain wear height and full-size grinding mileage verification experiments were conducted. The results indicated that the established model was in reasonable agreement with the experimental outcomes, which suggests that this model could be useful in the industry to predict the wear process of abrasive belts.
\end{abstract}

Keywords: abrasive belt; single grain cutting; slide wear; grinding mileage

\section{Introduction}

In the natural sciences, quantitative research involves the systematic empirical investigation of observable phenomena via statistical, mathematical or computational techniques. Modeling is the most frequently used method in quantitative research. Over the past decades, numerous researchers have provided remarkable contributions to modeling research on abrasive belt grinding processes. Models, such as a temperature model [1], material removal model [2], contact model [3, 4], topography model [5], residual stress model [6] and surface texture model $[7,8]$, have been successfully established. The purpose of such models is to determine accurate and concise relationships between grinding results and process parameters.

As with other tools, abrasive belts inevitably become blunt once they are put into use. Wear impairs the abrasive belt performance and prevents it from grinding further, which is detrimental to manufacturing precision. Furthermore, the geometry of the belt changes continuously due to wear. For any grinding belt model, the changing grain geometries reduce the model accuracy. Thus, proper dynamic compensation for geometric changes is necessary. An accurate wear model is the best choice to solve such problems. It can feed back to other models and improve their prediction accuracy. Thus, it is important to study the wear of abrasive belts in the grinding process. Unfortunately, there are nearly no complete models of abrasive belt wear in the existing literature. Although Bigerelle et al. [7] and Jourani et al. [8] mentioned wear modeling in their reports, the wear models presented were not fully functional because they were established as supplements to the main part of the authors' work.

For the wear modeling of tools, many attempts have been made to discover mathematical regularities underlying the wear phenomena. For example, Checkina

* Corresponding author: Yueming LIU, E-mail: liuym@bjtu.edu.cn 


\begin{tabular}{|c|c|c|c|}
\hline \multicolumn{4}{|c|}{ Nomenclature } \\
\hline$\alpha$ & Experimental coefficient of wear rate & $F_{\mathrm{t}}$ & Tangential grinding force \\
\hline$\gamma_{\mathrm{c}}$ & Poisson ratio of contact wheel & $f \dot{\varepsilon}$ & Strain rate sensitivity \\
\hline$\gamma_{\mathrm{w}}$ & Poisson ratio of workpiece & $g\left(\varepsilon^{\mathrm{p}}\right)$ & Strain hardening \\
\hline$\Delta \delta$ & Wear height & \multicolumn{2}{|c|}{ HV(temp) Temperature-dependent hardness } \\
\hline$\delta$ & Cutting depth & $h$ & Protrusion height of grains \\
\hline $\bar{\delta}$ & Average cutting depth & $h_{\mathrm{a}}$ & Average protrusion height of grains \\
\hline$\varepsilon$ & Workpiece strain & $h_{\max }$ & Maximum protrusion height of grains \\
\hline$\dot{\varepsilon}$ & Strain rate & $I_{\mathrm{v}}$ & Wear rate \\
\hline$\varepsilon^{\mathrm{p}}$ & Plastic strain & $j(h)$ & Grains' protrusion height distribution \\
\hline$\zeta$ & Mean square error (MSE) of protrusion height & $K_{\mathrm{c}}$ & Elasticity of contact wheel \\
\hline$\theta$ & Half of the grain tip wedge angle & $K_{\mathrm{lc}}$ & Fracture toughness of ceramic \\
\hline$\kappa$ & Thermal conductivity of ceramic & $K_{\mathrm{w}}$ & Elasticity of workpiece \\
\hline$\mu$ & Friction coefficient & $k_{\mathrm{e}}$ & Effective availability of grains \\
\hline$\sigma$ & Normal stress of workpiece & $l$ & Sliding distance \\
\hline$\sigma_{\max }$ & Ceramic maximum tensile stress & $l_{\mathrm{a}}$ & Length of abrasive belt \\
\hline$\tau$ & Sheer stress & $l_{\mathrm{b}}$ & Contact width \\
\hline$\tau_{0}$ & Critical shear stress & $l_{\mathrm{c}}$ & Contact length \\
\hline$\phi$ & Reference angle & $l_{\mathrm{m}}$ & Grinding mileage \\
\hline$\psi($ temp & Thermal softening & $N_{\mathrm{d}}$ & Number of active grains per unit area \\
\hline$\omega$ & Inclined angle of workpiece & $\mathrm{Rr}$ & Roughness of surface \\
\hline$A$ & Area of grain tip bearing the grinding force & $r$ & Distance from grain summit \\
\hline$a$ & Ratio of adhesion and sliding area & $r_{\mathrm{c}}$ & Poisson's ratio of contact wheel \\
\hline$a_{\mathrm{p}}$ & Grinding depth & $r_{\mathrm{w}}$ & Poisson's ratio of workpiece \\
\hline$c_{\mathrm{a}}$ & Modification coefficient & $s$ & Contact radius of single grain \\
\hline$d_{\mathrm{c}}$ & Diameter of contact wheel & $T_{0}$ & Ambient temperature \\
\hline$d_{\mathrm{g}}$ & Average diameter of ceramic crystal & temp & Grinding zone temperature \\
\hline$E_{\mathrm{c}}$ & Elasticity modulus of contact wheel & $V_{\mathrm{s}}$ & Wear volume of grain \\
\hline$E_{\mathrm{w}}$ & Elasticity modulus of workpiece & $V_{\text {sum }}$ & Total wear volume of grains \\
\hline$F_{1}$ & Grinding force caused by normal stress & $v_{\mathrm{s}}$ & Abrasive belt speed \\
\hline$F_{2}$ & Grinding force caused by shear stress & $v_{\mathrm{w}}$ & Workpiece speed \\
\hline$F_{\mathrm{n}}$ & Normal grinding force & $\bar{w}$ & Average width of chip \\
\hline
\end{tabular}

et al. [9] modeled tool wear in a rock cutting process. They obtained a tool profile degeneration curve in two-dimensions by considering the workpiece material properties and cutting force. Choudhury and Srinivas [10] established a predictive model of flank wear. The work included wear volume calculations that considered the cutting force and wear rate. Kishawy et al. [11] presented a wear mode for rotary tools, in which the authors mentioned that the specific work-tool material pair is important to the wear calculation. Zhang and Guo [12] built a flank wear model based on the cutting force and energy consumption. Another outstanding model presented by Li et al. [13] clarified the tool profile evolution due to flank wear. The model mainly involved calculation of the force exerted on the flank face, development of the geometric model of material loss due to flank wear and calculation of the wear rate.

In summary, the main steps of wear modeling involve the following elements: (1) calculation of the cutting force using a proper constitutive mode; (2) demonstration of the tool material loss in accordance with the wear 
rate. Although turning and grinding tools are quite different, as the latter has millions of cutting edges, the methodologies used for modeling turning tools are valuable to this work. Therefore, the development of single grain wear theories into a multiple grain grinding tool model is a key component of this work.

We established a wear model for an abrasive belt from the perspective of a single grain cutting process. Considering the constitutive model and interference action of a conical single grain, the cutting force for a single grain at a specified cutting depth was calculated by applying the stress integration method. Subsequently, based on the grinding force mentioned above and wear rate $\left(\mathrm{mm}^{3} / \mathrm{m}\right)$, a quantitative relationship between the scratch distance and wear height was derived accordingly. Finally, we obtained the relationship between the wear height and grinding mileage by extending the above conclusions to abrasive belts. To verify the proposed model, single scratch experiments and full grinding experiments were performed.

\section{Abrasive belt wear modelling}

\subsection{Single-grain cutting force model}

Grains suitable for use as abrasives must be significantly harder (by at least 20\%) than the workpiece material [14], with proper sizes and shapes to effectively promote material removal. In developing a wear and friction model that considers the grinding force between a grain and workpiece, a simplified grain shape, such as a sphere, cone or a pyramid, can be used [5, 15-17]. Grains are modeled differently depending on the size and objective of the study. To obtain an approximate ground surface of a workpiece, Li et al. [18] modeled grains as complicated truncated polyhedrons. To obtain the grinding force of a single grain, Zhang et al. [17] considered a cone-shaped grain. Generally, if the mesh size is bigger than $80 \#$ (such as 120\#), grains have been modeled as cones with a round tip [19, 20]. Otherwise, pointed cones are recommended because the tip radius can be neglected relative to the larger grain size. We used a grain size of $36 \#$ and $40 \#$ in our experiments. Hence, the grains in this study were modeled as pointed cones.

The cutting process of a grain tip depends on many parameters, such as the wedge angle of tip, sliding speed, depth of cut and spatial orientation. A previous report [21] discussed the influence of grain orientation on microcutting performance in detail. In our case, an abrasive belt was fabricated by static electricity grain planting technology. Most of the grains were vertically planted on the abrasive belt [22]. Thus, the spatial orientation was not a factor that was considered. As shown in Fig. 1, the process of grinding can be modeled by millions of cone tips with a wedge angle of $2 \theta$ making cuts to a certain penetration depths $\delta$ in a workpiece and sliding at a constant speed of $v_{\mathrm{s}}$, while the workpiece slides at a constant speed of $v_{\mathrm{w}}$ and counters against the grain tips. During this process, elastic or plastic deformation occurs in the workpiece material, leaving the surface with upheavals and grooves. In principle, each grain produces a different cutting depth that contributes differently to the total force value. However, the final aim of this study is modeling a multi-grain wear process during grinding. Therefore, it is not critical to represent each grain in the grinding zone. Thus, the average cutting depth $(\bar{\delta})$ was introduced in this study to avoid a discussion of the complicated cutting depths for each grain.

Another key factor of the single grain grinding force is the material property. First, workpiece strain $(\varepsilon)$ occurs when the grain tip slides against the workpiece (Fig. 2). Generally, the material is incompressible when plastic deformation occurs. Point $G(r / \sin \theta, \phi)$ on arc $A B C$ will slide to position $H(\delta / \cos \theta, \phi)$ along the line $\mathrm{OH}$ due to the force imparted by the grain tip. The strain, $\varepsilon$, can be expressed as

$$
\varepsilon=\frac{\overline{\mathrm{OH}}-\overline{\mathrm{OG}}}{\overline{\mathrm{OG}}}=\frac{\delta / \cos \theta-r / \sin \theta}{r / \sin \theta}=\frac{\delta}{r} \tan \theta-1
$$

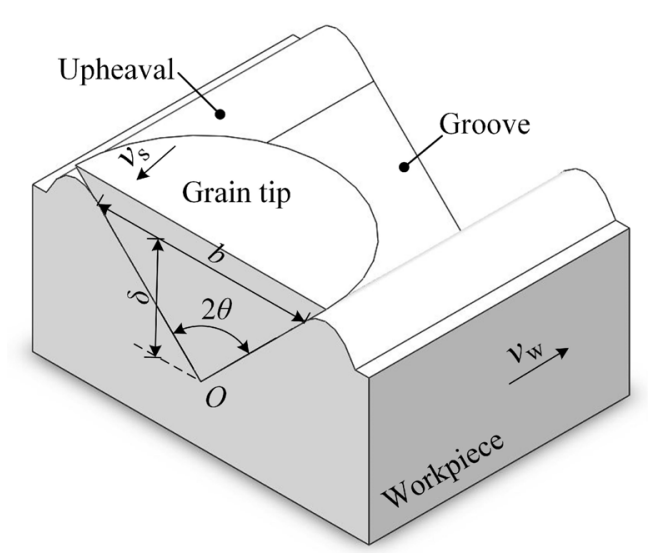

Fig. 1 Schematic diagram of the single grain grinding process. 


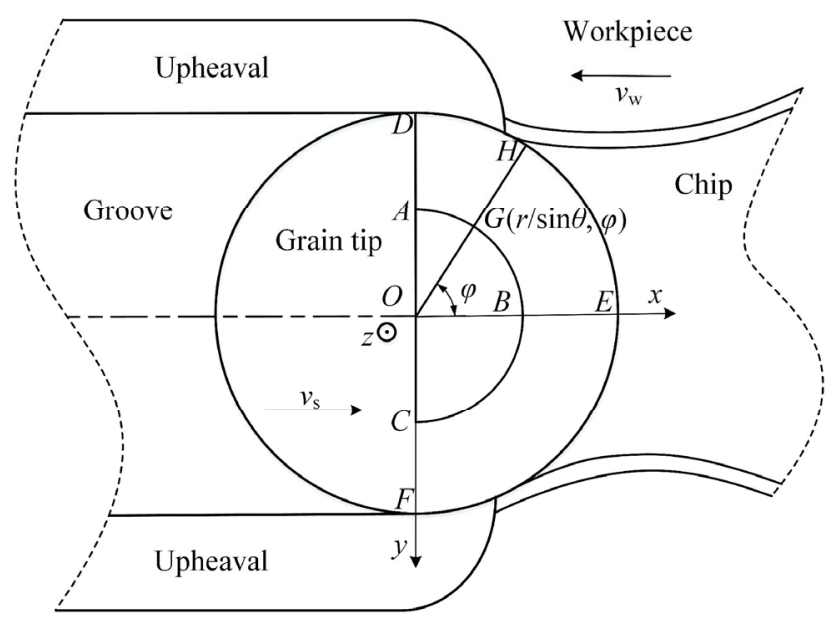

Fig. 2 Strain caused by grain tip (top view).

Secondly, a successful and reliable analytic force model depends on a constitutive model [23]. A variety of constitutive models [24] exist for the representation of engineering material behaviors where the strain rate and temperature effects cannot be neglected. These models are fit with experimental data (from the split Hopkinson pressure bar (SHPB) test, etc.), which can describe the effect of strain, strain rate and temperature on the material stress. The modified power-law model [25] is a universal constitutive model for various materials. The general expression of the model is

$$
\sigma=g\left(\varepsilon^{\mathrm{p}}\right) f(\dot{\varepsilon}) \psi(\text { temp })
$$

For U71Mn steel, Tian et al. [26] tested the mechanical properties of U71Mn with SHPB test apparatus. Zhang et al. [27] and Xi et al. [28] clarified the thermal softening function of U71Mn in detail. In this work, we used the data from the literature to build a constitutive model of the workpiece, as shown in Fig. (3).

As for the shear of the workpiece, Jiang [29] suggested that the relationship between stress and shear is

$$
\tau=\left\{\begin{array}{lll}
\tau_{0}, & \tau>\tau_{0} & \text { Adhesion friction } r<a \cdot \delta \tan \theta \\
\mu \sigma, & \tau<\tau_{0} & \text { Sliding friction others }
\end{array}\right.
$$

$\mu$ was determined by Jiang [29] empirically to be $\mu=$ $0.5233 v_{s}^{-0.04762} \sigma^{0.08923}$. Good agreement between experiments and predictions was achieved when $a$ was 0.25 .

In microscale grinding, when a hard conical tip cuts to the penetration depth and begins to move along the surface of a soft metal, as shown in Fig. 4, the elemental force, $\mathrm{d} F_{1}$, caused by the normal pressure and the

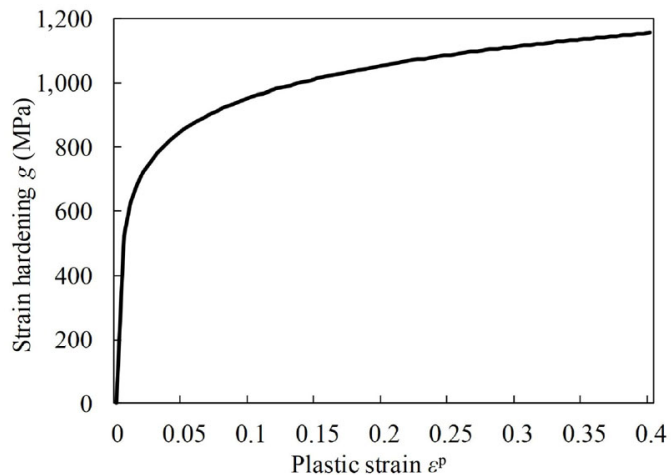

(a) Strain hardening

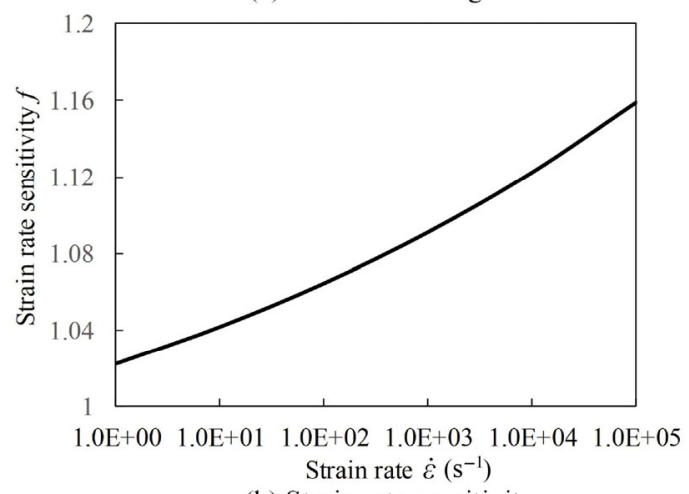

(b) Strain rate sensitivity

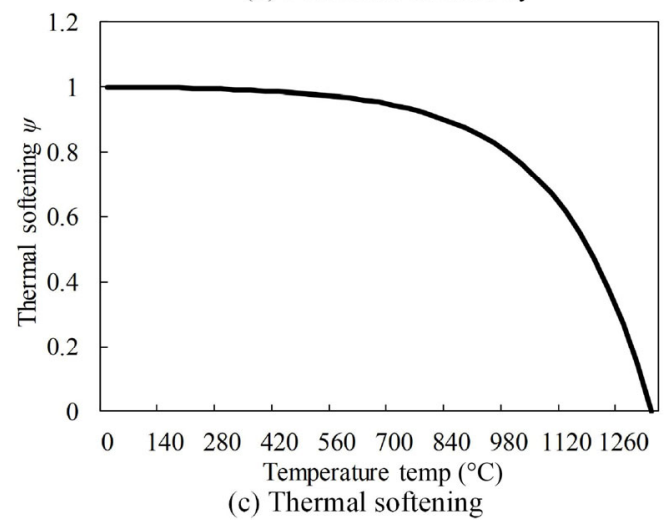

Fig. 3 (a) Strain hardening, (b) strain rate sensitivity, and (c) thermal softening for U71Mn.

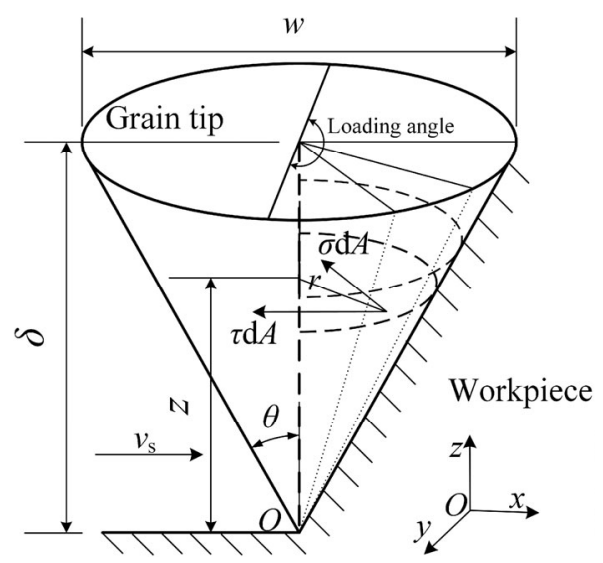

Fig. 4 Grinding force of a grain tip. 
tangential force component, $\mathrm{d} F_{2}$, caused by the shear stress acting on an element area, $\mathrm{d} A$, are determined by Eqs. (4) and (5), respectively:

$$
\begin{gathered}
\left\{\begin{array}{l}
\mathrm{d} F_{1}=\sigma \mathrm{d} A \\
\mathrm{~d} F_{2}=\tau \mathrm{d} A
\end{array}\right. \\
\mathrm{d} A=\frac{\pi r}{\cos \theta} \mathrm{d} z=\frac{\pi z \sin \theta}{\cos ^{2} \theta} \mathrm{d} z
\end{gathered}
$$

The total tangential and normal forces on an element are $\mathrm{d} F_{\mathrm{n}}$ and $\mathrm{d} F_{\mathrm{t}}$, respectively, and they are calculated as follows:

$$
\left\{\begin{array}{l}
\mathrm{d} F_{\mathrm{n}}=\mathrm{d} F_{1} \sin \theta+\mathrm{d} F_{2} \cos \theta \\
\mathrm{d} F_{\mathrm{t}}=\mathrm{d} F_{1} \cos \theta-\mathrm{d} F_{2} \sin \theta
\end{array}\right.
$$

Theoretically, since only the front half of a cone tip carries the force, the loading angle is equal to $\pi$. However due to elastic deformation of the workpiece, the loading angle increases slightly. To correct for this error, a modification coefficient $c_{\mathrm{a}}\left(c_{\mathrm{a}}>1\right)$ is introduced. The normal force, $F_{\mathrm{n}}$ and tangential force, $F_{\mathrm{t}}$, are obtained by evaluating the following integrals:

$$
\left\{\begin{array}{l}
F_{\mathrm{n}}=c_{\mathrm{a}} \cdot\left(\int_{0}^{\delta} \sigma \cdot \pi z \tan ^{2} \theta \mathrm{d} z+\int_{0}^{\delta} \tau \cdot \pi z \tan \theta \mathrm{d} z\right) \\
F_{\mathrm{t}}=c_{\mathrm{a}} \cdot\left(\int_{0}^{\delta} \sigma \cdot \pi z \tan \theta d z-\int_{0}^{\delta} \tau \cdot \pi z \tan ^{2} \theta \mathrm{d} z\right)
\end{array}\right.
$$

Naturally, wear changes the shape of the grain tip gradually, changing the grinding force on a single grain tip accordingly. The shape was assumed to change as illustrated in Fig. 5. An average cutting depth $(\bar{\delta})$ is required to determine the grinding force, which can be calculated as follows:

$$
\bar{\delta} \cdot \bar{w} \cdot l_{\mathrm{c}}=\frac{v_{\mathrm{w}} \cdot a_{\mathrm{p}}}{v_{\mathrm{s}} \cdot N_{\mathrm{d}}}
$$

Since a constant grinding pressure was applied in this work, the grinding depth $\left(a_{\mathrm{p}}\right)$ was measured using a laser sensor.

\subsection{Model of single grain wear height}

There have been many attempts to model the wear rate of various workpiece materials over a wide range of operating conditions [30-33]. Among them, Hsu and Shen [33] expressed the wear rate of ceramics

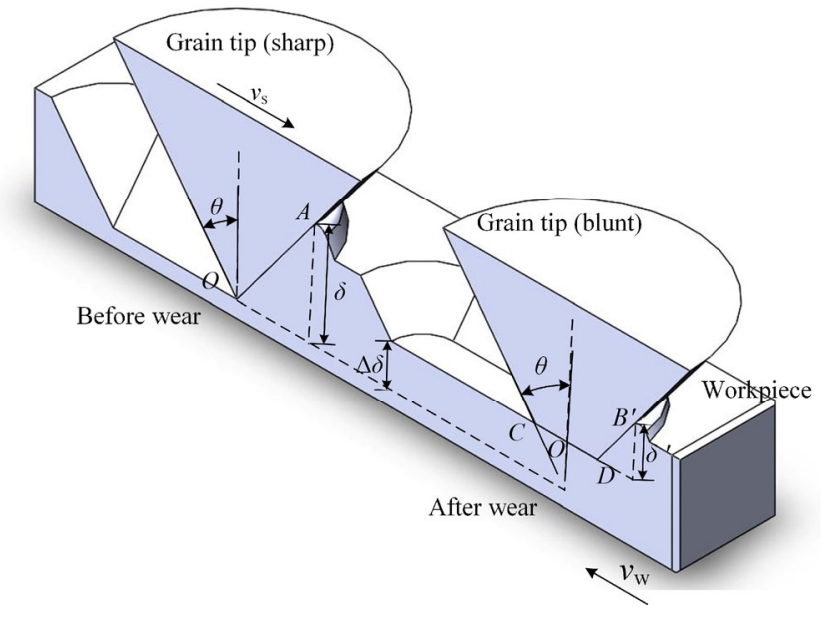

Fig. 5 Wear height of a single grain.

$\left(I_{V}=\mathrm{d} V / \mathrm{d} S\right.$, where $V$ is the wear volume $\left(\mathrm{m}^{3}\right)$, and $S$ is the sliding distance $(\mathrm{m})$ ) as a function of the cutting force and temperature as

$$
I_{\mathrm{v}}=\alpha \frac{\sigma_{\max }\left(\frac{\text { temp }}{T_{0}}\right) \sqrt{d_{\mathrm{g}}}}{k_{\mathrm{lc}}} \cdot \frac{F_{\mathrm{n}}}{\mathrm{HV}(\text { temp })}
$$

where $\mathrm{HV}($ temp $)=24 \mathrm{e}^{\text {temp }}$.

As shown in Fig. 5, the grain tip gradually becomes blunt when wear occurs, causing the tip shape to become a flat cone. According to the definition of wear rate, the relationship between wear height, $\Delta \delta$, and sliding distance, $l$, can be expressed as

$$
\Delta \delta=\sqrt[3]{\frac{3 I_{\mathrm{v}} \cdot l}{\pi \tan ^{2} \theta}}
$$

Therefore, if the normal force and basic mechanical properties of the ceramics are fully understood, the residual service life (the distance that the grain can cut) of a single grain can be modeled using Eq. (10). This may be a fundamental tool for the entire abrasive belt residual service life prediction, in which various single grains can be superimposed. It should be noted that the condition at the end of the residual service life is usually different for various process parameters, because it depends on how the "usable" wear height, $\Delta \delta$, is defined. Generally, the wear height, $\Delta \delta$, is larger when the normal force, $F_{\mathrm{n}}$, increases.

\subsection{Wear modeling of multiple grains}

Abrasive belt grinding is different from single abrasive 
grain cutting, and this difference is mainly reflected in the multi-cutting edge and various protrusion heights. In this section, a single-grain model is developed into a multi-grain model.

Since the contact wheel is covered with an elastic rubber layer, the deformation of the contact wheel may produce a considerable change to the real length of the contact zone by dramatically increasing the geometrical contact length. Rowe et al. [34] optimized the geometrical contact length by adding elastic characteristics and proposed that the real contact length, $l_{c}$ can be calculated as

$$
l_{\mathrm{c}}=\sqrt{a_{\mathrm{p}} d_{\mathrm{c}}+8 R r^{2} F_{\mathrm{n}} d_{\mathrm{c}}\left(K_{\mathrm{s}}+K_{\mathrm{w}}\right) / l_{\mathrm{b}}}
$$

Good agreement between the predicted and experimental contact lengths was found by Rowe and his co-workers [34] by setting $\mathrm{Rr}=5$. The wheel and workpiece elasticity $\left(K_{\mathrm{s}}\right.$ and $K_{\mathrm{w}}$, respectively) can be estimated by

$$
K_{i}=\frac{1-\gamma_{i}^{2}}{\pi E_{i}} \quad i=s(\text { contact wheel), } w \text { (workpiece) }
$$

It should be noted that although researchers have treated abrasive belts as elastic, the thickness of the rubber layer around the contact wheel is much thicker than the abrasive belt thickness. Furthermore, the rubber has a higher elasticity than abrasive belts. Thus, we neglected the influence of the abrasive belt elasticity on the contact area.

Generally, the protrusion height on the abrasive belt surface followed a Gaussian distribution. In our case, we paid more attention to the grains' contact with the workpiece. In terms of that part of the grains, their protrusion height still followed a Gaussian distribution. This is confirmed by Refs. [35, 36]. Hence, the probability density function $j(h)$ is as follows:

$$
j(h)= \begin{cases}\frac{1}{\sqrt{2 k \pi} \zeta} \exp \frac{-\left(h-h_{\mathrm{a}}\right)^{2}}{2 \zeta^{2}}, & |h| \leq 3 \zeta ; \\ 0, & |h|>3 \zeta\end{cases}
$$

If the height of the resin bond surface is 0 , then the maximum height of the grains is $h_{\max }=h_{\mathrm{a}}+3 \zeta$, and the volume of a single cone-shaped grain is

$$
V_{\mathrm{s}}=\frac{\pi h^{3}}{3} \tan ^{2} \theta
$$

Figure 6 is the interaction between the abrasive belt and workpiece. All the grains whose protrusion heights lie between $h_{\max }-\delta$ and $h_{\max }$ are involved in grinding. These grains inevitably become blunt leading to a decrease of their protrusion heights. During this process, the wear volume of all the grains involved in the grinding, $V_{\text {sum }}$ is

$$
V_{\text {sum }}=N_{\mathrm{d}} \cdot l_{\mathrm{c}} \cdot l_{\mathrm{b}} \int_{h_{\max }-\delta}^{h_{\max }} \frac{\pi}{3}\left[h-\left(h_{\max }-\delta\right)\right]^{3} \tan ^{2} \theta j(h) \mathrm{d} h
$$

As discussed in Section 2, the sliding distance of a grain is key to calculating the wear height. According to the kinematic relationship between the abrasive belt and workpiece, the grinding mileage, $l_{\mathrm{m}}$ and sliding distance, $l$, are related by

$$
l=\frac{l_{\mathrm{m}}}{l_{\mathrm{a}}} \cdot l_{\mathrm{c}}
$$

Based on the definition of wear rate $\left(I_{\mathrm{v}}\right)$ and by considering the effective availability of the grains $\left(k_{\mathrm{e}}\right)$, we obtained a model for evaluating the grinding mileage of multiple grains.

$$
l_{\mathrm{m}}=\frac{k_{\mathrm{e}} \cdot N_{\mathrm{d}} \cdot l_{\mathrm{a}} \cdot l_{\mathrm{b}} \int_{h_{\max }-\delta}^{h_{\max }} \frac{\pi}{3}\left[h-\left(h_{\max }-\delta\right)\right]^{3} \tan ^{2} \theta j(h) \mathrm{d} h}{I_{\mathrm{v}}}
$$

\section{Verification experiments}

The workpiece used in the experiments was made from U71Mn steel, which is widely used in high-speed railways in China. The elemental composition of this material in wt.\% is shown in Table 1, and its mechanical

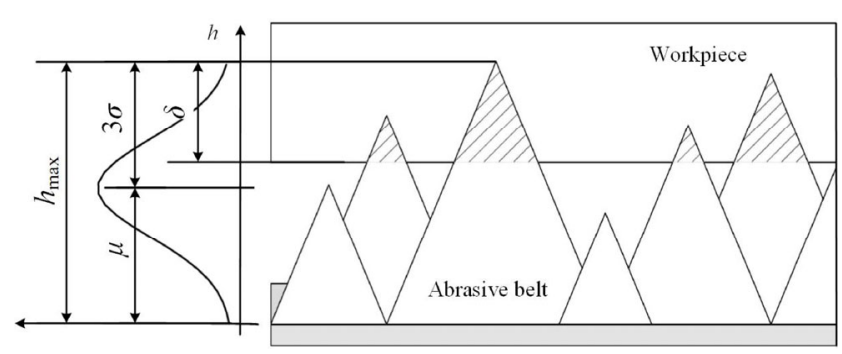

Fig. 6 Interaction between the abrasive belt and the workpiece. 
properties are summarized in Table 2. It is a typical hard grinding material due to the high content of $\mathrm{Mn}$.

A test specimen cube with a size of $15 \mathrm{~mm} \times 10 \mathrm{~mm} \times$ $3 \mathrm{~mm}$ was polished using abrasive paper, and the surface roughness $(\mathrm{Ra})$ was limited to values less than $0.2 \mu \mathrm{m}$, which may eliminate potential unexpected effects due to the surface roughness. The initial workpiece temperature was set to the ambient room temperature of $20^{\circ} \mathrm{C}$.

In cutting force verification experiments, a scratch apparatus CAS WS-2005 (shown in Fig. 7) equipped with two force sensors was used. The normal force sensor could measure a normal load of 0-200 N with a resolution of $0.1 \mathrm{~N}$; and the tangential force sensor could measure a tangential force of $0-100 \mathrm{~N}$ with a resolution of $0.05 \mathrm{~N}$. The grain material was alumina. Relevant properties of this abrasive material are summarized in Table 3. Two different grain tips were used in the experiments with wedge angles of $120^{\circ}$ and $90^{\circ}$. The constant sliding speed in the experiments was $10 \mathrm{~mm} / \mathrm{s}$. It should be noted that the specimen was not parallel to the clamp, as there was a small angle, $\omega$, between them. The sliding distance, $l$, and cutting depth, $\delta$, were expressed as $\delta=l \cdot \tan \omega$. Thus, the force at various cutting depths could be collected with only one experiment.

In the single grain wear height verification experiments, to prevent fracture, the grain tip was loaded at a normal force of $10 \mathrm{~N}$ with a sliding speed of $10 \mathrm{~mm} / \mathrm{s}$. The ceramic tip with a $120^{\circ}$ wedge angle slid repeatedly, as the $120^{\circ}$ wedge angle is closer to the average wedge angle of abrasive belt grains. In this case, the angle

Table 1 Elemental composition (wt.\%) of the workpiece

\begin{tabular}{ccccccc}
\hline Material & $\mathrm{C}$ & $\mathrm{Si}$ & $\mathrm{Mn}$ & $\mathrm{S}$ & $\mathrm{P}$ & $\mathrm{Fe}$ \\
\hline U71Mn & $0.65-0.76$ & $0.15-0.35$ & $1.10-1.40$ & $\leq 0.02$ & $\leq 0.03$ & Balanced
\end{tabular}

Table 2 Physics properties of the workpiece

\begin{tabular}{cc}
\hline Parameters & Value \\
\hline Density $\rho\left(\mathrm{g} / \mathrm{cm}^{3}\right)$ & 7.74 \\
Hardness $(\mathrm{HRC})$ & 23.3 \\
Linear expansivity $\lambda\left(\mathrm{K}^{-1}\right)$ & $1.17 \times 10^{-5}(293 \mathrm{~K})$ \\
Specific heat $C(\mathrm{~J} /(\mathrm{g} \cdot \mathrm{K}))$ & 0.46 \\
Elastic modulus $E(\mathrm{GPa})$ & 233 \\
Poisson ratio $v$ & 0.316 \\
Thermal conductivity $\kappa(\mathrm{W} /(\mathrm{m} \cdot \mathrm{K}))$ & $15(293 \mathrm{~K})$ \\
\hline
\end{tabular}
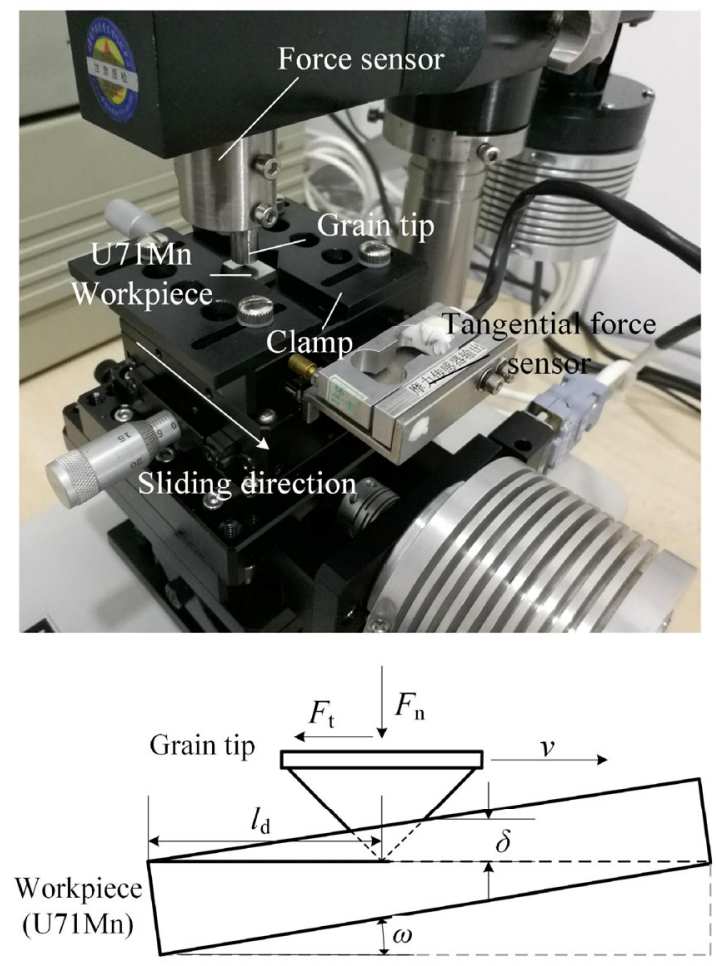

Fig. 7 CAS WS-2005 scratch apparatus and experiment settings.

Table 3 Mechanical properties of alumina.

\begin{tabular}{cc}
\hline Items & Values \\
\hline Maximum tensile stress $\sigma_{\max }(\mathrm{MPa})$ & 350 \\
Thermal conductivity $\kappa(\mathrm{W} /(\mathrm{m} \cdot \mathrm{K}))$ & 29.3 \\
Hardness $(\mathrm{HRC})$ & 70 \\
Average diameter of crystal $d_{\mathrm{g}}(\mu \mathrm{m})$ & 3 \\
Fracture toughness of $K_{\mathrm{lc}}\left(\mathrm{MPa} \cdot \mathrm{m}^{0.5}\right)$ & 5.85 \\
Poisson ratio $v$ & 0.24 \\
Elastic modulus $E(\mathrm{GPa})$ & 330 \\
\hline
\end{tabular}

between the clamp and workpiece was zero $\left(\omega=0^{\circ}\right)$. The grain tip was firmly fixed by a holder through which a constant load was exerted. The position of the end of the holder was used to determine the wear height of the tip. The experiments were stopped at regular time intervals during which the wear height, $\Delta \delta$, and sliding distance, $l$, were recorded by a microscope.

In full-size grinding mileage prediction experiments, an abrasive belt grinding apparatus (shown in Fig. 8(a)) was applied. Motor $\mathrm{A}$ in the apparatus drove the driving wheel, causing the abrasive belt to rotate at a high velocity, while motor $B$ was responsible for driving the circular U71Mn workpiece. The cylinder forced 


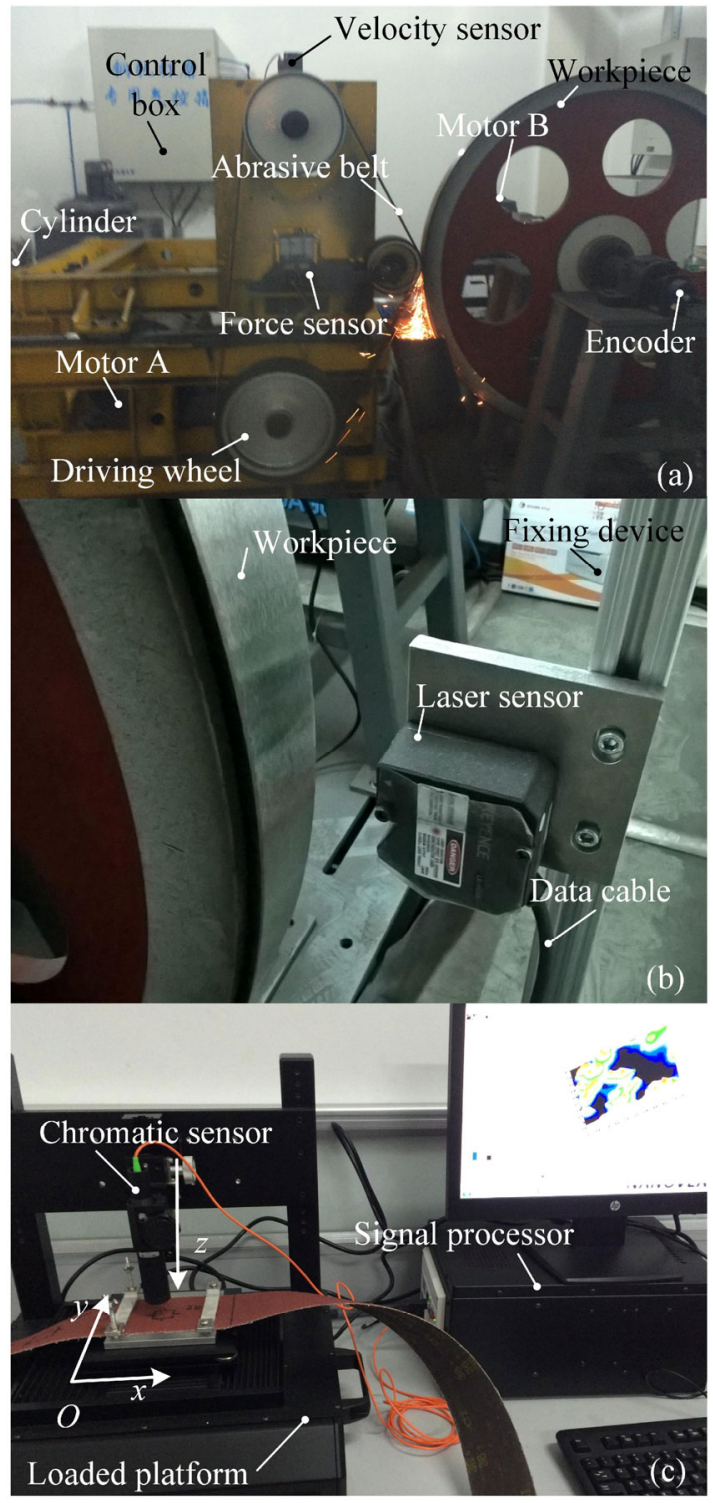

Fig. 8 Devices for grinding experiments: (a) grinding apparatus, (b) laser sensor, and (c) optical profilometer.

the abrasive belt to contact the workpiece during grinding. During the grinding process, all the process parameters were controlled by a control box, and they were monitored by multiple sensors feeding back measurement data in real time. The abrasive belt velocity was monitored by a velocity sensor. An encoder was used to help collect the velocity data accurately. A force sensor was fixed to the contact wheel to collect the force data exerted by the cylinder. All the data was transferred to the control box via a data cable. The grinding apparatus provided sufficient velocity and contact normal force data through various sensors for subsequent analysis.
To determine the grinding depth of the abrasive belt $\left(a_{\mathrm{p}}\right)$, the laser sensor shown in Fig. 8(b) was used to monitor the distance between the sensor and workpiece with $0.5 \mu \mathrm{m}$ of accuracy. Thus, the grinding depth $\left(a_{\mathrm{p}}\right)$ was obtained according to the distance measured by the laser sensor before and after grinding.

The grinding process was stopped at a regular time intervals, during which an optical profilometer (Fig. 8(c)) scanned the surface of the abrasive belt to calculate the wear height. The profilometer tested the stochastic surface at a maximum size of $50 \mathrm{~mm} \times 50 \mathrm{~mm}$ with an accuracy of $5 \mathrm{~nm}$. We randomly selected 5 scanning areas of $10 \mathrm{~mm} \times 10 \mathrm{~mm}$ on the abrasive belt surface. Using a method proposed in Ref. [5], both the probability density of the protrusion height $j(h)$ and the average wear height were calculated unambiguously.

Two new, commercially available abrasive belts were chosen for each experiment, and they were numbered 1 and 2. The two abrasive belts had different grain sizes, but the grains coated on the abrasive belts' surface were constructed from the same abrasive material. The average wedge angles of grains were calculated following Wang's work [5]. Detailed information of the abrasive belts is summarized in Table 4 along with the process parameters adopted in the experiments.

\section{Results and discussion}

\subsection{Single-grain cutting force}

Based on the demonstration discussed in Section 1, we calculated the normal and tangential forces of a

Table 4 Grinding mileage experiments.

\begin{tabular}{ccc}
\hline Experiments number & 1 & 2 \\
\hline Grain size & 36 & 40 \\
Normal load $(\mathrm{N})$ & 400 & 250 \\
Abrasive belt speed $(\mathrm{m} / \mathrm{s})$ & 30 & 20 \\
Workpiece speed $(\mathrm{m} / \mathrm{s})$ & 0.25 & 0.25 \\
Abrasive material & Alumina & Alumina \\
Abrasive belt size $\left(\mathrm{mm}^{2}\right)$ & $3,000 \times 70$ & $3,000 \times 70$ \\
Average wedge angle of abrasive & $117^{\circ}$ & $104^{\circ}$ \\
grains $\left({ }^{\circ}\right)$ & 758 & 354 \\
Initial protrusion height $(\mu \mathrm{m})$ & 0.27 & 0.55 \\
\hline Number of active grains per area $\left(/ \mathrm{mm}^{2}\right)$ & &
\end{tabular}


single cone grain for various cutting depths ranging from 10 to $30 \mu \mathrm{m}$. Figure 9(a) shows the normal and tangential forces when the wedge angle of the grain tip is $120^{\circ}$. Both the normal and tangential forces of the grain tip increased nonlinearly with an increase of cutting depth. The tangential force was smaller than the normal force in every case, which indicates that the friction coefficient $\left(F_{\mathrm{t}} / F_{\mathrm{n}}\right)$ was less than 1 for all of the cases. Subsequently, the errors between theoretical and experimental results increased, but the average relative error was still smaller than $13.4 \%$. Figure $9(\mathrm{~b})$ shows the forces of the $90^{\circ}$ grain tip. Compared with Fig. 9(a), smaller forces were measured to achieve the same cutting depths because the smaller wedge angle corresponds to a sharper tip, which can cut into workpiece more easily. The average relative error is approximately $13 \%$. The theoretical curves exhibited fairly good agreement with the experimental results.
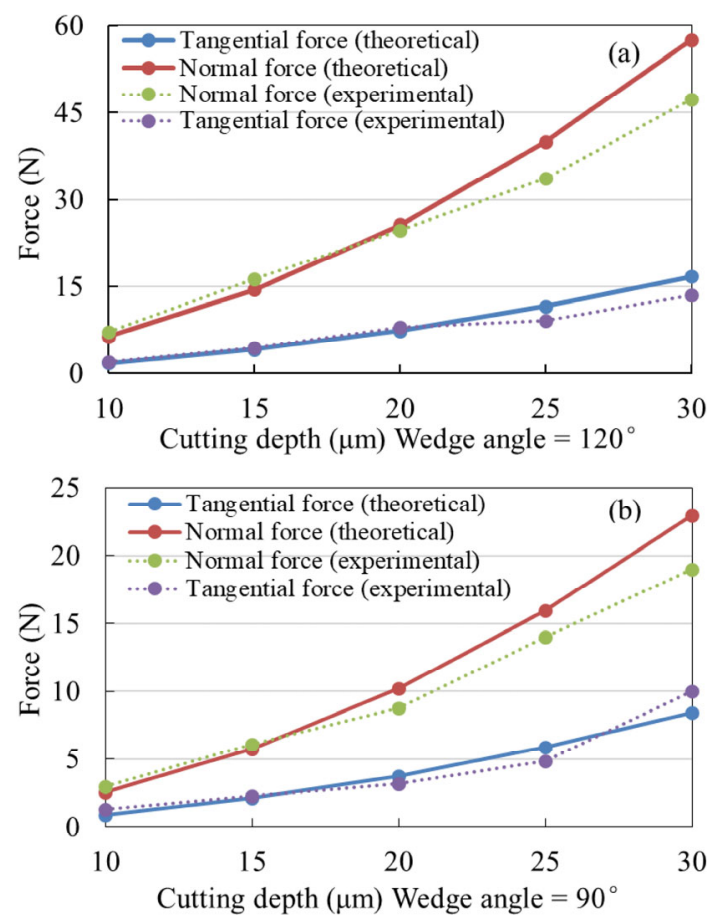

Fig. 9 Grinding force for wedge angles of (a) $120^{\circ}$ and (b) $90^{\circ}$.
Based on these results, we could estimate the wear rate of ceramics for the wear height experiments.

\subsection{Wear height of a single grain}

Figure 10 is the exemplary picture of an alumina tip before and after wear. Once the sharp tip was put into use, wear occurred as the tip slid repeatedly under the selected process parameters. The tip was the first part to be affected, it flattened, and its protrusion height decreased. This phenomenon is normal and inevitable resulting in shape change of tips, which is a significant cause of the impaired grinding ability of abrasive belts. As the wear is aggravated, this phenomenon became more obvious.

Figure 11(a) shows the scanning electron microscopy (SEM) images of a blunt area with smooth and irregular grooves. The blunt area was dominated by extremely fine microgrooves that were nearly identical in pitch and depth. The orientation of microgrooves, which are $0.8 \mu \mathrm{m}$ wide, was parallel to the sliding direction. Most of the microgrooves were inerratic, with distinct edges (shown in Fig. 11(b)). Occasionally, some irregular microgrooves were observed, which may have resulted from local fractures of the alumina ceramics (shown in Fig. 11(c)).

We measured the wear height of the alumina with the $120^{\circ}$ wedge angle at regular sliding distance intervals. Based on Eq. (10), with an experimental coefficient of wear rate $(\alpha)$ of $7.5 \times 10^{-9}$, the theoretical value of wear height for alumina is presented in Fig. 12. As we can see, the wear heights increased with an increase of the sliding distance, but the increasing rate of wear rate obviously decreased. Furthermore, the experimental values showed good agreement with the theoretical values, which suggested that the prediction model for ceramic wear height was valid. This will make a positive contribution to further predictions of the grinding mileage of an entire abrasive belt in full-size experiments.

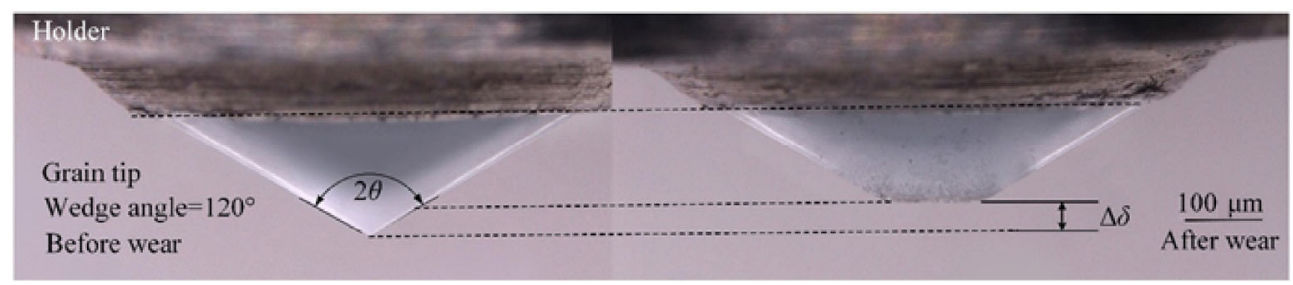

Fig. 10 Wear height of alumina ceramics. 


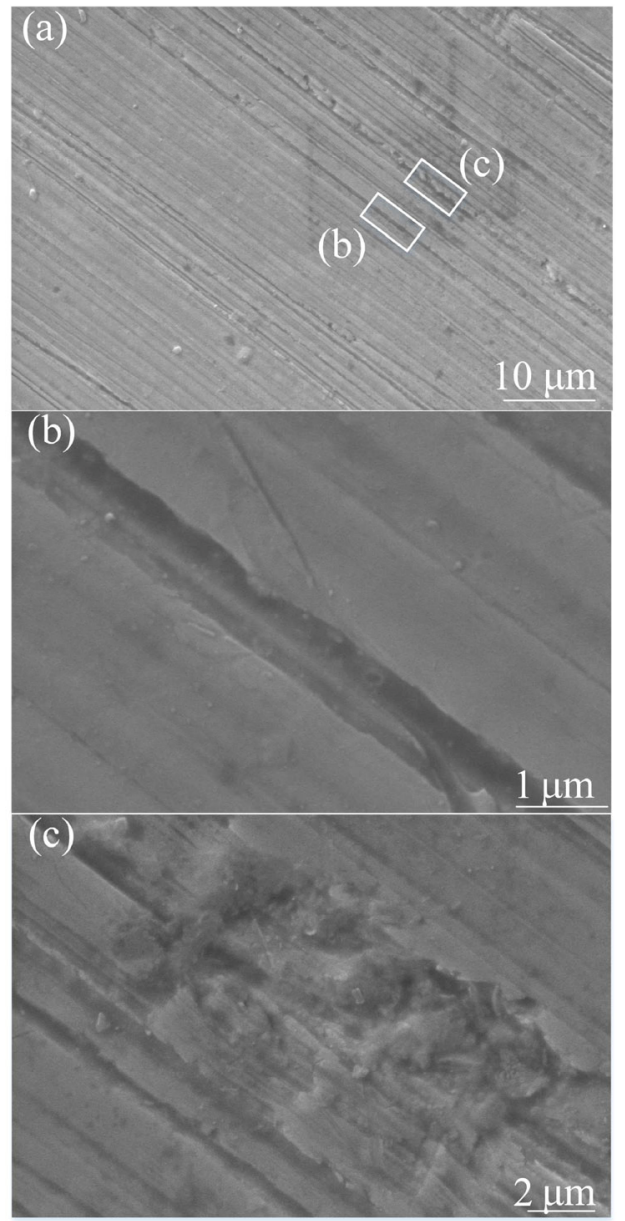

Fig. 11 SEM pictures of (a) blunt areas, (b) smooth grooves, and (c) irregular grooves.

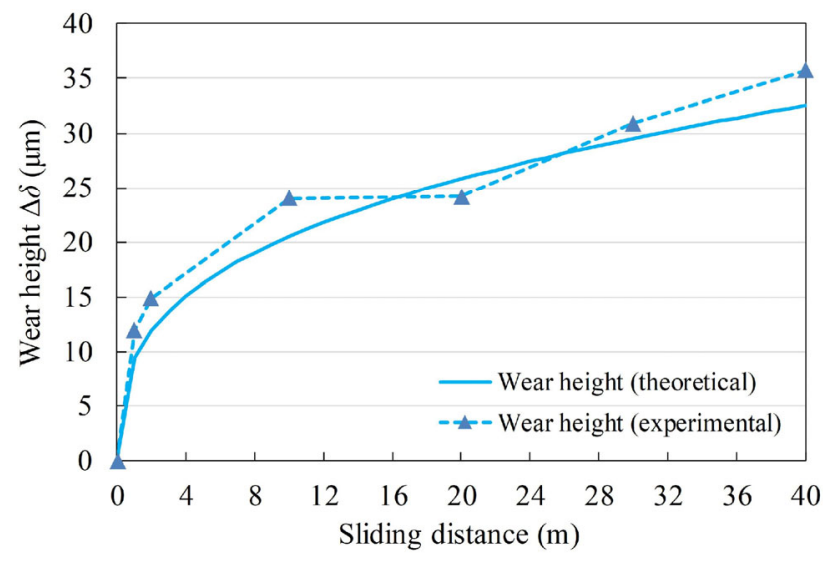

Fig. 12 Single grain wear height under various sliding distances.

\subsection{Abrasive belt grinding mileages}

The results of the full-size grinding mileage experiments are shown in Fig. 13. Referring to Wang's work [36], the effective availability of grains $\left(k_{\mathrm{e}}\right)$ equals to 0.9 . We measured the workpiece surface temperature during

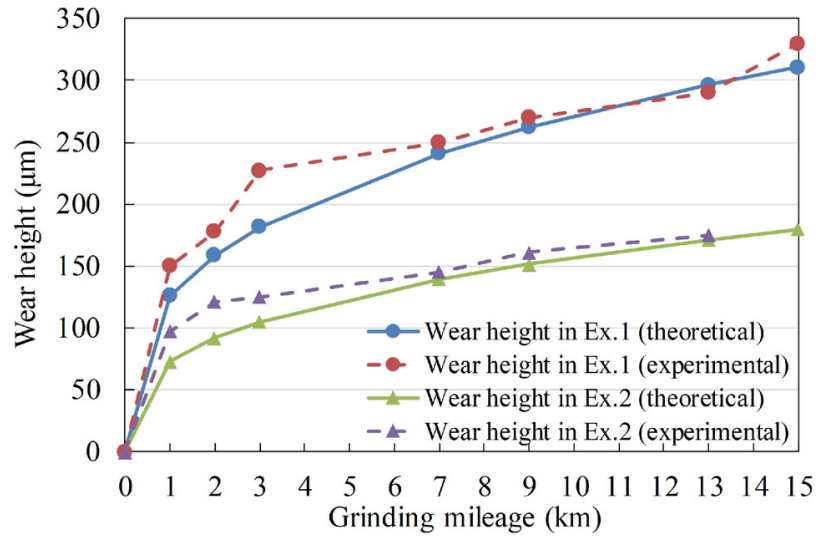

Fig. 13 Abrasive belt wear height versus grinding mileage.

the steady grinding stage, and this temperature was used to modify the material properties. The two abrasive belts showed clear differences in wear heights. The abrasive belt (36\#) with abominable grinding parameters was severely worn in Experiment 1, and it exhibited a greater wear height under the same grinding mileages compared to that of Experiment 2. The average wear height of the abrasive belt exhibited a nonlinear correlation with the grinding mileage. Compared to the single grain wear experiments discussed above, the wear regularity was extremely similar. There were obvious turning points for the two types of abrasive belts after a grinding mileage of approximately $3.3 \mathrm{~km}$. In the first $3.3 \mathrm{~km}$, differences between the experimental and theoretical values were visible in Experiments 1 and 2. However, the experimental values showed good correlations with the theoretical values after the turning points $(3.3 \mathrm{~km})$.

The reasons for this are as follows. When a new abrasive belt is put into use, the grain tips are tiny and brittle. Consequently the normal load is concentrated on the tiny tips. Brittle wear is inevitable, leading to the wear height increasing dramatically. However, after the turning points, blunt areas formed and concentrated load phenomenon was alleviated, which suggested that the wear of grain tips was mild and the consumption of abrasive material slowed.

In addition, in the experiments, the initial protrusion heights of the abrasive belts were not completely consumed in the grinding process. In the termination of the grinding process, at least $40 \%-55 \%$ of the protrusion height was retained. At that time, the material removal ratio decreased to one-sixth of the maximum material removal ratio, which resulted in a 
negative effect on the working efficiency. Therefore, in this paper, we propose that a protrusion height reduction of approximately $50 \%$ of the initial height is characteristic of the abrasive belt life ending.

We established a model of cutting force of a single grain. Then, based on the basic mechanical properties of the abrasive material, the wear rates of ceramics were determined. Consequently, the wear height-sliding distance model was built. Finally, we developed a model for the entire abrasive belt to evaluate the grinding mileage. In industry, this brings at least 3 applications that are as follows: (1) When the wear height reaches approximately half of the initial protrusion height, this corresponds to the end of abrasive belt life. This criterion depends on the process parameters and how the "end" of an abrasive belt is defined. (2) The grinding mileage model can estimate grinding mileage of a new abrasive belt if the basic abrasive and process parameters are known. (3) Based on the wear height, workers can evaluate the residual service life of abrasive belts and decide when used abrasive belts should be replaced.

\section{Conclusions}

In this study, a model for wear evaluation and modeling was established. The relevant results were developed for multiple grains to predict the grinding mileages of abrasive belts. The conclusions are as follows:

(1) An analytical cutting force model for a single grain was built for a simplified grain tip. It quantitatively predicts microgrinding forces incorporating the material properties with consideration of the power-law constitutive model of U71Mn. The verification experiments showed that the magnitudes of the predicted forces agreed well with the experimental data. As the cutting depth increased, the grinding force became increasingly nonlinear. At the same cutting depth, the tip with the $120^{\circ}$ wedge angle exhibited a greater grinding force than that of the $90^{\circ}$ tip in the normal and tangential directions. The tangential force was usually smaller than the normal force, which indicates that the friction coefficient $\left(F_{\mathrm{t}} / F_{\mathrm{n}}\right)$ was less than 1 .

(2) Based on the grinding force model, the relationship between the individual grain's wear height and sliding distance was reported. This was verified using a cone ceramic tip sliding on an U71Mn specimen repeatedly. The blunt area is a feature of abrasive wear. It comprises many fine microgrooves. The edges of the microgrooves were distinct and regular in most cases.

(3) As a further advancement, the relevant results for a single grain were extended for multiple grains. A method for predicting the grinding mileage using the average wear height was proposed accordingly. Full-size experiments demonstrated that there were differences between the predicted and experimental values in the first $3.3 \mathrm{~km}$. After that, the differences subsequently decreased. Fracture of the grains resulting from load concentration in the initial stages of grinding was the reason for this difference.

Future works based on this study will focus on revealing the abrasion wear mechanism of abrasive grains at the microscale level.

\section{Acknowledgements}

The first author of this paper (Zhe He) would like to acknowledge the financial support from "China Scholarship Council (201707090012)" which helped his stay in Japan for this joint international research. This paper is supported by "the Fundamental Research Funds for the Central Universities" (2018JBZ105) and Natural Science Foundation of Tianjin (No. 15JCQNJC04800).

Open Access: This article is licensed under a Creative Commons Attribution 4.0 International License, which permits use, sharing, adaptation, distribution and reproduction in any medium or format, as long as you give appropriate credit to the original author(s) and the source, provide a link to the Creative Commons licence, and indicate if changes were made.

The images or other third party material in this article are included in the article's Creative Commons licence, unless indicated otherwise in a credit line to the material. If material is not included in the article's Creative Commons licence and your intended use is not permitted by statutory regulation or exceeds the permitted use, you will need to obtain permission directly from the copyright holder.

To view a copy of this licence, visit http://creativecommons.org/licenses/ by/4.0/. 


\section{References}

[1] Jourani A. Three dimensional modelling of temperature distribution during belt finishing. Int $J$ Surf Eng 9(2-3): 231-246 (2015)

[2] Pandiyan V, Caesarendra W, Tjahjowidodo T, Praveen G. Predictive modelling and analysis of process parameters on material removal characteristics in abrasive belt grinding process. Appl Sci 7(4): 363 (2017)

[3] He Z, Li J Y, Liu Y M, Nie M, Fan W G. Investigating the effects of contact pressure on rail material abrasive belt grinding performance. Int $J$ Adv Manuf Technol 93(1-4): 779-786 (2017)

[4] Xiao G J, Huang Y. Experimental research and modelling of life-cycle material removal in belt finishing for titanium alloy. J Manuf Processes 30: 255-267 (2017)

[5] Wang W X, Li J Y, Fan W G, Song X Y, Wang L F. Characteristic quantitative evaluation and stochastic modeling of surface topography for zirconia alumina abrasive belt. Int $J$ Adv Manuf Technol 89(9-12): 3059-3069 (2017)

[6] Rech J, Kermouche G, Grzesik W, García-Rosales C, Khellouki A, García-Navas V. Characterization and modelling of the residual stresses induced by belt finishing on a AISI52100 hardened steel. J Mater Process Technol 208(1-3): 187-195 (2008)

[7] Bigerelle M, Hagege B, El Mansori M. Mechanical modelling of micro-scale abrasion in superfinish belt grinding. Tribol Int 41(11): 992-1001 (2008)

[8] Jourani A, Dursapt M, Hamdi H, Rech J, Zahouani H. Effect of the belt grinding on the surface texture: Modeling of the contact and abrasive wear. Wear 259(7-12): 1137-1143 (2005)

[9] Checkina O G, Goryacheva I G, Krasnik V G. The model for tool wear in rock cutting. Wear 198(1-2): 33-38 (1996)

[10] Choudhury S K, Srinivas P. Tool wear prediction in turning. J Mater Process Technol 153-154: 276-280 (2004)

[11] Kishawy H A, Pang L, Balazinski M. Modeling of tool wear during hard turning with self-propelled rotary tools. Int J Mech Sci 53(11): 1015-1021 (2011)

[12] Zhang G C, Guo C S. Modeling flank wear progression based on cutting force and energy prediction in turning process. Proced Manuf 5: 536-545 (2016)

[13] Li G X, Li N, Wen C E, Ding S L. Investigation and modeling of flank wear process of different PCD tools in cutting titanium alloy Ti6A14V. Int J Adv Manuf Technol 95(1-4): 719-733 (2018)

[14] Torrance A A. An explanation of the hardness differential needed for abrasion. Wear 68(2): 263-266 (1981)

[15] Wang S, Li C H, Zhang X W, Jia D Z, Zhang D T, Zhang Q. Modeling and simulation of the single grain grinding process of the Nano-particle jet flow of minimal quantity lubrication. Open Mater Sci J 8: 55-62 (2014)

[16] Hisakado T, Suda H. Effects of asperity shape and summit height distributions on friction and wear characteristics. Wear 225-229: 450-457 (1999)

[17] Zhang Y B, Li C H, Ji H J, Yang X H, Yang M, Jia D Z, Zhang X P, Li R Z, Wang J. Analysis of grinding mechanics and improved predictive force model based on material-removal and plastic-stacking mechanisms. Int J Mach Tools Manuf 122: 81-97 (2017)

[18] Li H Y, Li X K, Chen Z, Liu X L, Wang L P, Rong Y M. The simulation of surface topography generation in multi-pass sanding processes through virtual belt and kinetics model. Int J Adv Manuf Technol 97(5-8): 2125-2140 (2018)

[19] Anderson D, Warkentin A, Bauer R. Comparison of spherical and truncated cone geometries for single abrasive-grain cutting. J Mater Process Technol 212(9): 1946-1953 (2012).

[20] Jourani A. A new three-dimensional numerical model of rough contact: Influence of mode of surface deformation on real area of contact and pressure distribution. J Tribol 137(1): 011401 (2015)

[21] Li X K, Lu Y P, Li Q, Li F, Rong Y K. The study on the influences of superabrasive grain spatial orientation for microcutting processes based on response surface methodology. Int J Adv Manuf Technol 67(5-8): 1527-1536 (2013)

[22] He Z, Li J Y, Liu Y M, Nie M, Fan W G. Modeling of virtual topography of abrasive belt. J South China Univ Technol (Nat Sci Ed) 45(12): 85-91, 105 (2017)

[23] Lin Y C, Chen X M, Liu G. A modified Johnson-cook model for tensile behaviors of typical high-strength alloy steel. Mater Sci Eng: A 527(26): 6980-6986 (2010)

[24] Lin Y C, Chen X M. A critical review of experimental results and constitutive descriptions for metals and alloys in hot working. Mater Des 32(4): 1733-1759 (2011)

[25] Jiang F, Li J F, Sun J, Zhang S, Wang Z Q, Yan L. A17050-T7451 turning simulation based on the modified power-law material model. Int J Adv Manuf Technol 48(9-12): 871-880 (2010)

[26] Tian Y, Cheng Y R, Liu X W. Studies on the dynamic behavior of U71Mn rail steel under high strain rates. China Railway Sci 13(2): 34-42 (1992)

[27] Zhang Y H, Zhou Q Y, Chen Z Y, Liu F S, Zhou Z G. Study on properties of rail U71Mn at low temperatures. $J$ China Railway Soc 27(6): 21-27 (2005)

[28] Xi W, Wang Y Q, Shi Y J. Experimental study on the mechanical properties of rail steel at low temperature. $J$ Railway Eng Soc (8): 25-29 (2006)

[29] Jiang F, Yan L, Xu X P, Rong Y M. Mechanical model of contact stress distribution between cutting tool and chip. $J$ Mech Eng 50(5): 188-193 (2014) 
[30] Evans A G, Wilshaw T R. Quasi-static solid particle damage in brittle solids-I. Observations analysis and implications. Acta Metall 24(10): 939-956 (1976)

[31] Drozdov Y N, Nadein V A, Savinova T M. Predicting the frictional wear rate of industrial ceramics. Russ Eng Res 28(6): 554-558 (2008)

[32] Kim S S, Kim S W, Hsu S M. A new parameter for assessment of ceramic wear. Wear 179(1-2): 69-73 (1994)

[33] Hsu S M, Shen M. Wear prediction of ceramics. Wear 256(9-10): 867-878 (2004)

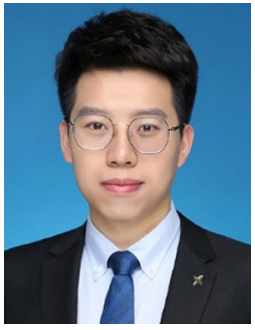

Zhe HE. He obtained his bachelor degree in 2014 from Beijing Jiaotong University. He worked with Prof. Jiwang YAN as a visiting researcher

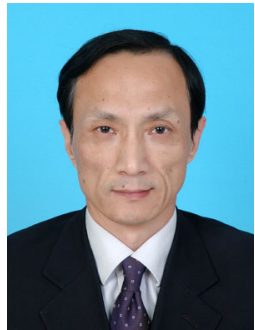

Jianyong LI. He obtained his bachelor of engineering degree and master degree in 1983 and 1986 from Tianjin University, respectively. After that, he obtained his Ph.D. degree in 2003 from Beijing Jiaotong University.

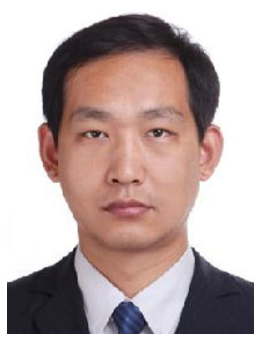

Yueming LIU. He obtained his bachelor degree in 2007 from Shenyang Ligong University, master degree and Ph.D. degree in 2009 and

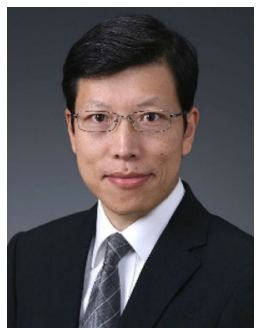

Jiwang YAN. He obtained his bachelor degree and master degree in 1991 and 1993 from Jilin University, respectively. He obtained his Ph.D. degree in 2000 from Tohoku University. His interested research
[34] Rowe W B, Morgan M N, Qi H S, Zheng W H. The effect of deformation on the contact area in grinding. CIRP Ann 42(1): 409-412 (1993)

[35] Wang R Q. The modeling and experimental research of belt-grinding process in rail grinding. Master's thesis. Beijing (China): Beijing Jiaotong University, 2016.

[36] Wang W X, Li J Y, Fan W G, He Z. Abrasion process modeling of abrasive belt grinding in rail maintenance. $J$ Southwest Jiaotong Univ 52(1): 141-147 (2017)

in Keio University in Japan during 2017-2018. His interested research areas include abrasive belt grinding, wear mechanism of abrasive belt and rail grinding.

His interested research areas include high speed grinding technology used in rail grinding and high precision process used in semiconductor machining process. He successively presided and participated in many research projects and published around 40 journal papers.

2013 from Northeastern University, respectively. His interested research areas include rail maintenance technology, high speed grinding technology and functional surface polishing technology.

areas include ultraprecision and nano manufacturing, laser processing of material, micro forming, imprinting and molding. He has participated in many international projects and has published more than 30 papers in international journals in recent 2 years. 